\title{
DO TERRITÓRIO USADO À MULTITERRITORIALIDADE: REFLEXÕES SOBRE O LAZER E O TURISMO EM SEGUNDAS RESIDÊNCIAS NO NORDESTE BRASILEIRO*
}

\author{
Lenilton Francisco de Assis**
}

\section{RESUMO}

O artigo apresenta uma análise preliminar sobre os velhos e novos usos das segundas residências no Nordeste brasileiro, adotando como matriz teórica o território usado e a multiterritorialidade. Para tanto, retoma alguns fundamentos ontológicos e epistemológicos para justificar o emprego de tais categorias/conceitos na Geografia.

\section{PALAVRAS-CHAVE}

Território usado; multiterritorialidade; segunda residência; turismo; Geografia.

\section{ABSTRACT}

The article presents a preliminary analysis on the old and new uses of second homes in northeastern of Brazil. Used territory and multiterritoriality form the theoretical basis for this analysis that reviews some ontological and epistemological approaches to justify the employment of these categories/concepts in Geography.

\section{KEY WORDS}

Used territory; multiterritoriality; second home; tourism; Geography.

\section{Introdução}

As ideias desenvolvidas no presente artigo partem de inquietações sobre o espaço geográfico no período atual da Globalização, quando a técnica e a política constituem o pano de fundo para uma discussão sobre o seu uso, ou melhor, sobre o território usado. A adoção dessa categoria cunhada por Santos e Silveira (2001) nos permitiu fazer algumas mediações teórico-práticas entre os objetos e as ações que intensificam/ diversificam o uso do território para o lazer e o turismo em segundas residências.

Compreender os velhos e novos usos do território pelas segundas residências é um desafio que nos colocamos, motivados pelas existências contemporâneas que permitem à sociedade, como nunca antes, vivenciar uma pluralidade de territórios ou uma multiterritorialidade. A associação dessa metáfora/conceito proposta por Haesbaert (2006) levou-nos a realizar, inicialmente, uma discussão onto-epistemológica sobre o emprego de categorias, conceitos e metáforas na Geografia; e a desenvolvermos, na sequência, uma análise preliminar sobre as segundas residências no Nordeste brasileiro.

\section{Do território multiterritorialidade: pressupostos ontológicos e epistemológicos}

A busca pelo conhecimento do mundo é um dos fundamentos da ciência. A realidade e sua dinâmica estão sempre instigando os

* Este texto é uma versão revista e ampliada do trabalho de conclusão da disciplina Questões de Método em Geografia, ministrada pela Profa. Dra. María Laura Silveira, no segundo semestre de 2007, na Pós-graduação em Geografia Humana da USP.

** Professor Assistente do Curso de Geografia da Universidade Estadual Vale do Acaraú (UVA - Sobral/CE); Doutorando em Geografia Humana na USP; Bolsista do CNPq - Brasil. E-mail: Ienilton@yahoo.com 
cientistas a formularem e reformularem teorias, equações, modelos e esquemas abstratos de referência empírica. É um constante ir e vir do saber, no qual o conhecimento produzido é a base para as novas descobertas que emanam dos problemas sociais.

A ciência, embora seja uma das mais extraordinárias criações do homem, "não é o lugar das certezas absolutas", como nos lembra Granger (1994, p. 113). Os conhecimentos científicos são sempre parciais e relativos, já que evoluem a partir das constantes revisões epistemológicas e ontológicas que têm a Filosofia como vanguarda.

A ontologia é conhecida como a Filosofia primeira, a metafísica que se preocupa com o ser (essência) das coisas; "trata-se daquele saber que antecederá os saberes específicos" (MARTINS, 2007 , p. 34). Já a epistemologia busca construir uma teoria do conhecimento, a partir da análise dos princípios, métodos e resultados das ciências (JAPIASSU, 1991).

Apesar desses distintos enunciados, a ontologia e a epistemologia têm funções complementares na construção do saber, pois como ressalta Silva (1986, p. 25), "[...] não existe ontologia que não se dê primeiro como epistemologia e, portanto, como teoria do conhecimento, gnosiologia, lógica e metodologia". Isso se justifica porque toda reavaliação do corpus de uma ciência, do seu ser, requer uma discussão sobre o seu objeto e sua existência, ou seja, sobre o sistema de categorias, conceitos e métodos de análise que Ihe dá operacionalidade e coerência - interna e externa ${ }^{1}$.

É a Filosofia que alimenta o debate inter e transdiciplinar e, consequentemente, a interlocução entre a ontologia e a epistemologia. A Filosofia sempre foi considerada a mãe de todas as ciências, adjetivo esse que Ihe trouxe interpretações equivocadas de ser ela a responsável pela reflexão dos fundamentos de cada ciência em específico.

Contrapondo-se a isso, Sartre já alertava que "é chegado o tempo em que cada disciplina constrói sua própria filosofia" (apud SANTOS,
$1988 a$, p. 11). Mas essa tarefa epistemológica específica não decretaria a morte da Filosofia?

Acreditamos que não, pois a Filosofia invoca uma permanente reflexão sobre os problemas humanos de uma época, sobre as ideias e categorias que perpassam os conhecimentos específicos. Japiassu (1991, p. 193) esclarece que:

O papel da Filosofia é o de manter a abertura do espaço epistemológico. Ela deve criar um horizonte comum que recuse a todo confinamento. Não pode curvar-se a uma epistemologia qualquer, pois deve ser a "epistemologia de todas as epistemologias", isto é, o lugar onde as epistemologias se neutralizam umas às outras naquilo que possuem de excessivo. Mas também o lugar onde as epistemologias devem fecundar-se mutuamente, não se esquecendo jamais de sua obediência ao humano.

Nessa perspectiva, Santos (1988a, p. 11) ao defender o debate filosófico na Geografia ressalta que "não se pode pedir ao filósofo para escrever em um jargão de geógrafo. [...] A teoria geográfica tem de ser buscada no seu domínio próprio: o espaço. A Filosofia pode ser um guia, mas os filósofos não nos oferecem respostas [...]".

A reflexão filosófica quase sempre foi negligenciada na Geografia, em detrimento dos estudos empíricos, das descrições dos fatos naturais e humanos que guardavam pouca relação entre si. Haesbaert (2006, p. 17) chega mesmo a afirmar que "o distanciamento da Geografia em relação às bases filosóficas que norteiam o processo de elaboração do conhecimento é, certamente, responsável por grande parte de nossa fragilidade em termos de uma postura crítica e efetivamente transformadora". Fragilidade essa que também tem cerceado um debate mais amplo da Geografia com as demais Ciências Humanas.

Então, pensar a Geografia com as contribuições da Filosofia, ou melhor, buscar construir uma ontologia do espaço, foi e ainda é um desafio enfrentado por poucos geógrafos do país, dentre os quais se destacam Silva (1978; 
1986), com suas inquietações pioneiras, e Santos (1988a; 1997) - que pôde compartilhá-las e aprofundá-las².

\section{De acordo com Silva (1978, p. 128):}

Hoje, propõe-se uma ontologia do lugar que deve ser, antes do mais, uma ontologia do espaço. [...] Uma das tarefas principais é "pôr de pé" a reflexão filosófica a partir da preocupação do espaço como ser. [...] Tratase de construir um conhecimento geográfico a partir de uma visão não fragmentada do mundo, trabalho que vem sendo realizado agora, a partir do momento em que os geógrafos percebem que as idéias têm lugar em Geografia.

No afã de superar essa visão fragmentada de mundo (tão presente na Geografia Clássica e Moderna), Santos (1988a, p. 12) também defende que "uma Filosofia da geografia deve-se alimentar, em primeiro lugar, da noção de totalidade". Esta categoria abrangente permite um tratamento objetivo do atual período da Globalização que é marcado pela convivência de uma universalidade empírica, graças aos avanços da técnica, da ciência e da informação.

A operacionalização da totalidade, como recurso de método geográfico, deve partir do lugar e das suas articulações com o mundo, ou seja, de um movimento dialético entre o universal e o particular que tem nos eventos e na divisão territorial do trabalho algumas mediações para análise.

A totalidade, assim posta, apresenta-se como um caminho para reacender o debate filosófico na Geografia contemporânea e para construir uma ontologia do espaço - já que Santos (1997, p. 16) mais uma vez nos alerta que "na realidade, o corpus de uma disciplina é subordinado ao objeto e não o contrário".

O objeto da Geografia, o espaço, sempre suscitou discussões controversas no seio dessa disciplina e entre outras ciências (SANTOS; SOUZA, 1986; SANTOS, 1988b). Esse debate foi e ainda é alimentado por questionamentos sobre a suposta unidade do espaço, em contraponto aos diferentes métodos utilizados pela Geografia Física e Humana. Também ecoam críticas, dentre outras, ao caráter sintético, abrangente e descritivo da Geografia.

A crise de paradigmas que assola as Ciências Humanas na contemporaneidade também repercute entre os geógrafos, ensejando alguns confrontos e debates entre distintas correntes de pensamento. Na Geografia brasileira, podemos dizer que essa crise se traduz em duas linhas de análise: uma crítica à Geografia Crítica e a sua imposição como dogma que não possibilita uma reavaliação da disciplina diante da nova dinâmica da Globalização e de outros métodos de investigação (como os defendidos pela Geografia Física, Cultural e Humanista); e o movimento inverso, dos que admitem a existência de uma crise da Geografia Crítica, ocasionada pelo abandono do marxismo e pelo refluxo do pensamento crítico e radical (CARLOS, 2007) que tem sucumbido a uma Geografia Aplicada, parcelar, que dispensa a teoria e se deixa seduzir pelos encantos do mercado, levando à segmentação da realidade e da própria ciência geográfica ${ }^{3}$.

A construção de uma ontologia do espaço (que seja uma teoria social e contemple a multiplicidade do mundo e das maneiras de entendê-lo) permitiria à Geografia, em tese, suplantar algumas dessas críticas e querelas. Mas, defende Martins (2007) que restringir ao espaço o debate sobre a essência (ser) e a existência (ente), na Geografia ${ }^{4}$ é um "equívoco subjacente", pois como esclarece o autor:

Qual a existência que define a essência desse ser que o espaço supostamente é? Por assim dizer, no debate geográfico, espaço é um ser de um ente, ou seja, é como se pudéssemos afirmar que um ente é espaço, que seu ser é espaço. [...] Confundir existência com essência, ou mesmo categoria com conceito é não discernir entre estar/ter e ser. Ainda que sejam aspectos indissolúveis, e mutuamente determinantes, não podemos confundi-los na definição ôntica do ente, nem na definição ontológica do ser. [...] Espaço só poderá ser essência enquanto ente ideal, ou seja, como 
algo diante da Idéia que necessita ser definido. Fora isso, ante os entes materiais ele é categoria, propriedade fundamental de tudo que Existe (MARTINS, 2007, p. 34-35. Grifo nosso).

Sob a forte influência marxista da década de 1980, Costa e Moraes (1984) também colocaram essas questões e se propuseram a realizar uma ontologia do espaço que definisse para a Geografia um objeto dotado de existência concreta e individualidade diante das demais ciências. Para eles, o objeto da Geografia não poderia estar no espaço tomado em si mesmo, mas na relação sociedade/espaço, ou melhor, no processo social de valorização do espaço.

Dessas provocações ontológicas (que são muito salutares à crítica e ao avançar da Geografia!), emerge uma discussão basilar sobre as categorias e os conceitos fundadores dessa disciplina, especialmente sobre o rigor do seu uso e das suas definições.

Categoria e conceito são dois termos que guardam certa sinonímia no vocabulário científico. A distinção entre eles, geralmente, só ocorre no plano filosófico, onde também não se encontra uma solução satisfatória, como podemos observar nas definições abaixo:

Categorias são conceitos fundamentais que determinam um tipo mesmo de objeto científico (GRANGER, 1994, p. 111. Grifo nosso).

Não há conceito simples. Todo conceito tem componentes, e se define por eles (DELEUZE; GUATTARI, 2007, p. 27). O conceito é o contorno, a configuração, a constelação de um acontecimento por vir. Os conceitos, neste sentido, pertencem de pleno direito à Filosofia, porque é ela que os cria, e não cessa de criálos. [...] Destacar sempre um acontecimento das coisas e dos seres é a tarefa da Filosofia quando cria conceitos, entidades (Ibidem, $p$. 46. Grifo nosso).

O conceito, na concepção de Deleuze e Guattari, é uma entidade metafísica, um "conhecimento do conhecimento", que se assemelha, em muitos aspectos, ao que outros autores denominam de categorias filosóficas, ou seja, aqueles conhecimentos universais abstratos que se tornam concretos pela práxis, dando subsídios às disciplinas para formularem suas categorias e conceitos específicos.

As duas definições acima também atestam o quanto é difícil precisar uma distinção entre conceitos e categorias, no âmbito da Filosofia. Mas, de uma maneira geral, podemos depreender que as categorias se sobrepõem aos conceitos, embora também os complemente. Althusser (1976, p. 27), ao destacar a importância de uma "Filosofia espontânea das ciências", já sinalizava para esse fato, ao dizer que "a Filosofia enuncia teses que reúnem e produzem não conceitos científicos, mas categorias filosóficas".

Portanto, podemos entender as categorias como noções mais sólidas e abrangentes que consolidam uma ciência ao longo do tempo. Isso não quer dizer que as categorias sejam estáticas ao movimento da sociedade. Ao contrário, elas adquirem status ontológico (de essência), exatamente, por acumularem maior carga de reflexões inter e transdisciplinares. Já os conceitos, são representações mais concretas do pensamento; são recortes mais empíricos do real que dão operacionalidade às categorias e, logo, à ciência. Eles expressam noções científicas mais fluidas e flexíveis à dinâmica social, com maior poder de se impor e se transformar diante da realidade.

Longe de esgotarem o debate, essas definições parciais nos ajudam a refletir sobre as provocações supracitadas por Martins (2007), de que, na Geografia, não se pode atribuir ao espaço um estatuto ontológico, de ser e ente, de categoria e conceito.

Vale lembrar, na citação grifada acima, que esse mesmo autor reconhece existência e essência, categoria e conceito, como aspectos indissolúveis e mutuamente determinantes como já dissemos alhures.

Nesse sentido, ao mesmo tempo em que o espaço é "forma e modos de ser" (SILVA, 1986), ele também é um conjunto particular de determinações, ou seja, de conteúdos que dão 
vida às formas. Santos (1988b, p. 16) explica que "o conteúdo corporificado, já transformado em existência, é a sociedade já distribuída dentro das formas geográficas, a sociedade que se torna espaço". Essa existência (ou forma-conteúdo) pode ser apreendida por diversos conceitos como: território, paisagem, lugar, região, etc ${ }^{5}$. Tais conceitos ou recortes espaciais dão maior operacionalidade ao espaço que é a categoria filosófica, abstrata e abrangente da Geografia.

Entretanto, definir o espaço como objeto da Geografia não esgota os questionamentos se ele é o objeto em si, se é a relação sociedade/ espaço ou a relação sociedade/natureza. Prosseguir na construção de uma ontologia do espaço é um caminho para superar tais questões e, provavelmente, formular outras. Como um dos principais expoentes desse debate na Geografia brasileira, Santos (1997, p. 16) destaca que:

É indispensável uma preocupação ontológica, um esforço interpretativo de dentro, o que tanto contribui para identificar a natureza do espaço, como para encontrar as categorias de estudo que permitam corretamente analisá-lo. Essa tarefa supõe o encontro de conceitos, tirados da realidade, fertilizados reciprocamente por sua associação obrigatória, e tornados capazes de utilização sobre a realidade em movimento. A isso também se pode chamar a busca de operacionalidade, um esforço constitucional e não adjetivo, fundado num exercício de análise da história (Grifo nosso).

Esse esforço interpretativo de dentro da Geografia é motivado pela realidade externa a essa ciência, pelas novas questões e problemas que o mundo propõe no presente. "Como a realidade é dinâmica, os conceitos devem dar conta do movimento" (SILVEIRA, 2003, p. 18).

Destarte, essa constante busca pela operacionalidade geográfica tem rebatimentos imediatos nas categorias e conceitos que tendem a mudar de conteúdo/significado e/ou a ser substituídos pelas metáforas. Estas são usadas pelas ciências para adjetivar um pensamento novo que ainda carece de maior fundamentação teórico-metodológica.
As limitações explicativas das metáforas, muitas vezes, as transformam em noções efêmeras. Mas elas também podem se consolidar como conceitos e categorias científicas, sendo assim elementos constitutivos da evolução do conhecimento.

O emprego de metáforas é mais habitual nas Ciências Humanas. Na Geografia, muitas delas são frequentemente criadas ou tomadas de empréstimo de outras disciplinas (a exemplo de fim do Estado, aldeia global, desterritorialização, não-lugares, etc.), denunciando um certo descuido epistemológico da Geografia em não refletir, internamente, sobre algumas metáforas citadas e em continuar com o "exercício de fabulações" (SANTOS, 2000).

O uso excessivo das metáforas, em qualquer ciência, é sempre uma operação de risco à banalização das categorias e conceitos, com a perda das suas coerências interna e externa. Por isso, Santos (1997, p. 15) adverte que "[...] nestes tempos acelerados, o tropel dos eventos desmente verdades estabelecidas e desmancha o saber. Mas a moda avassaladora das citações frescas não pode eliminar os debates inspirados em idéias filosóficas cuja lição não é circunstancial".

Preocupado em formular uma Geografia do Presente baseada numa revisão rigorosa sobre as noções fundadoras de uma ontologia do espaço, Santos (1997) apresenta na sua clássica obra, A natureza do espaço, diversas metáforas - rugosidade, forma-conteúdo, meio técnicocientífico-informacional, verticalidade, horizontalidade, território usado, espaço banal, espaço luminoso, espaço opaco, etc. - que adquiriram o status de conceitos e categorias geográficas, a partir do esforço epistemológico empreendido por este Autor ao longo das últimas três décadas do século passado.

Santos (1997, p. 171) mesmo chamou atenção para o fato de que "a metáfora é um elemento do discurso, mas não pode substituir o conceito, a teoria, a explicação. Recurso de estilo, ela pode ajudar o entendimento de uma situação, mas não toma o lugar da explicação. E esta é 
inspirada no próprio funcionamento das coisas ou das situações".

No bojo das categorias, conceitos e metáforas geográficas, o território ${ }^{6}$ se destaca, na atualidade, como um conceito que retorna ao centro dos debates nas Ciências Humanas, com maior capacidade de apreender as relações de poder que se manifestam no espaço geográfico, nas múltiplas escalas e dimensões de análise (naturalista, política, econômica e cultural).

O território sempre teve na Geografia uma forte conotação política e naturalista, herdada das contribuições de Ratzel e do seu pioneirismo em vincular o solo (espaço físico, ambiente ou território) ao Estado, determinando uma relação de dependência deste àquele. Para Ratzel (1983, p. 94-96), "[...] o Estado não pode existir sem um solo. [...] A tarefa do Estado, no que concerne ao solo permanece sempre a mesma em princípio: o Estado protege o território contra os ataques externos que tendem a diminuí-lo".

Ao superestimar a importância do território para o desenvolvimento do EstadoNação, Ratzel foi responsabilizado (com certo exagero!) por naturalizar a Geografia Política e também o território. Suas ideias alimentaram algumas teses expansionistas e beligerantes, provocando, consequentemente, uma retração nas análises espaciais da política e na evolução do conceito de território.

Após décadas sendo preterido pela categoria espaço (que se tornou objeto da Geografia Crítica), o território ressurge no debate geográfico a partir das novas leituras ${ }^{7}$ sobre 0 poder, ou como diz Foucault (2001), sobre os "poderes" que emanam das diversas esferas e instituições que regulam a vida em sociedade. Raffestin (1993) foi um dos principais geógrafos ${ }^{8}$ a propor, numa perspectiva relacional (política, econômica e cultural), uma discussão do território que considerasse as múltiplas dimensões e escalas de poder através das quais os grupos sociais dominam e se apropriam de uma determinada porção do espaço.

Território e espaço não são sinônimos e Raffestin (1993, p. 143) deixou claro essa diferença ao afirmar que "o território se forma a partir do espaço, é o resultado de uma ação conduzida por um ator sintagmático (ator que realiza um programa) em qualquer nível. Ao se apropriar de um espaço, concreta ou abstratamente $[\ldots]$, o ator 'territorializa' o espaço".

O espaço é muito mais amplo que o território, embora o primeiro não deva ser apenas entendido como o substrato do segundo. O espaço geográfico é, essencialmente, um espaço produzido pela sociedade, tendo a natureza como condição concreta da produção social.

A Geografia do Poder de Raffestin (1993) propunha ir além de uma Geografia do Estado (atrelada a Ratzel), libertando o território de uma visão restrita à delimitação das fronteiras do território nacional. Com essa abordagem, as escalas de análise ampliaram-se, incorporando ao território outros temas e dimensões - dos microterritórios das prostitutas, camelôs e taxistas aos macroterritórios do narcotráfico, multinacionais e grupos terroristas.

As territorialidades cíclicas e móveis (SOUZA, 1995) também trouxeram uma riqueza de situações para a análise geográfica que passou a incorporar outras referências de tempo e espaço. O território ainda se elasteceu das áreas e zonas contíguas (rigidamente marcadas pelas fronteiras) para os pontos e linhas que formam as redes e articulam múltiplos territórios.

Toda essa complexidade dos territórios ganhou força no último quartel do século $X X$ quando a "sociedade informacional, global e em rede" (CASTELLS, 2002) fez erigir uma multiplicidade de poderes que têm resultado em novos usos do território e na sua elevação ao posto de categoria geográfica - território usado (SANTOS; SILVEIRA, 2001; SANTOS, 2002) - assim como à profusão de diversas metáforas e/ou mitos como fim dos territórios, desterritorialização, desenraizamento, reterritorialização e multiterritorialidade (HAESBAERT, 2006; SAQUET, 2007).

Entender esses novos processos e usos do território é um desafio que nos colocamos, em seguida, motivados pelas existências 
contemporâneas que permitem à sociedade experimentar, mais intensamente, uma pluralidade de territórios ou uma multiterritorialidade. Esta metáfora geográfica, proposta por Haesbaert $(2005 ; 2006)$, já teria, hoje, a potência analítica e operacional de um conceito? Ou a força ontológica de uma categoria que fundamente uma Geografia do Presente?

Antes de buscarmos possíveis respostas para essas questões, vale considerarmos a pertinente advertência do próprio Haesbaert (2007, p. 3):

Hoje, num mundo de "hibridismo" como o nosso, os conceitos estão longe de carregar a ambição formal de outrora, e às vezes também aqui precisamos trabalhar muito mais com intersecções e ambivalências do que com fronteiras ou limites claramente definidos. Por isso, falamos no caráter contrastivo dos conceitos, num sentido que pode lembrar (sem radicalizar) a diffèrance de Derrida, onde um acabará sempre sendo (re)definido pelo outro numa resignificação sempre em aberto.

Nessa perspectiva, território usado e multiterritorialidade serão tratados aqui como conceitos híbridos e relacionais que trazem a possibilidade de explicar o mundo atual, a partir de uma releitura dos seus significados ou mesmo da associação com outros conceitos e metáforas.

Portanto, sem desprezarmos a importância de outras atividades (como as finanças, os transportes, as telecomunicações, o comércio, etc.), delimitaremos o lazer e o turismo em segundas residências como recortes empíricos para as breves reflexões, a seguir, sobre o território usado e a multiterritorialidade.

\section{Segundas residências e multiterritorialidade no Nordeste brasileiro: uma análise preliminar}

As segundas residências são conhecidas como habitações temporárias de lazer ocupadas nos de finais de semana, feriados e férias anuais. Geralmente, elas se localizam em áreas não muito distantes da primeira residência, onde as amenidades naturais (praia, montanha, campo) são os principais atrativos. Em muitos estudos, as segundas residências também são classificadas como alojamentos turísticos sem suscitar maiores discussões.

Em que pesem as polêmicas técnicas e conceituais, consideramos que esses domicílios ocasionais tanto são habitações de lazer quanto alojamentos turísticos. Precisar as distinções entre ambos tem sido um desafio perseguido por diversos pesquisadores (ASSIS, 2003; 2006; ANDREU, 2005), sobretudo considerando que além do tradicional veraneio nas casas de praia e campo, a segunda residência, hoje, também é bastante procurada por turistas que preferem adquirir um imóvel nos condomínios que aliam infraestrutura residencial e hoteleira (condoresorts).

As segundas residências estão, na sua essência, associadas à expansão do urbano e à formação de áreas residenciais segregadas. As modernas redes de informação e transporte globalizam a segunda residência, fazendo com que elas se multipliquem pelo mundo, notadamente nos países desenvolvidos, onde a melhor distribuição de renda permite a um maior contingente populacional o acesso a estas habitações.

Nos países em desenvolvimento, as segundas residências também estão em expansão. No litoral do Nordeste brasileiro, por exemplo, o crescente interesse dos turistas internacionais em adquirir um imóvel particular para uso nas férias tem transformando as segundas residências na nova atração do mercado imobiliário.

O número de domicílios de uso ocasional (segundas residências), no Nordeste, subiu de 116.938 para 552.198, entre 1980 e 2000, registrando uma taxa de crescimento anual de $8 \%$ que foi superior à média do país $(6,9 \%)$ para o mesmo período (ASSIS, 2006, p. 298).

De acordo com a Associação para o Desenvolvimento Imobiliário e Turístico do Nordeste Brasileiro' (ADIT), "entre 2000 e 2003, o número de turistas com casa própria no 
Nordeste brasileiro cresceu cerca de 200\% enquanto o de turistas que ficaram hospedados em hotéis caiu 12,5\%" (PETERSEN, 2006, p. 25).

O capital imobiliário local que, desde a década de $1950^{10}$, produz as tradicionais casas de praia e de serra para o lazer e o veraneio da elite nordestina, nas últimas décadas, vem se fundindo ao capital financeiro global (dos bancos privados e das cadeias hoteleiras internacionais) para investir, com o incentivo do Poder Público, na construção e venda de residências secundárias, especialmente em condo-resorts para turistas estrangeiros.

Casas e apartamentos de diversos padrões são ofertados pelas imobiliárias e resorts, sobretudo através do sistema de Tempo Compartilhado (Timeshare), em que o comprador paga uma fração do valor do imóvel e uma taxa de manutenção anual para ter o título de propriedade de uma unidade habitacional em um resort, totalmente equipada e mobiliada.

Os turistas estrangeiros que compram imóveis no Nordeste preferem os empreendimentos em condomínios devido à redução dos custos de manutenção, à maior segurança e à crescente valorização imobiliária. Esses novos usos da segunda residência têm levado a um casamento entre o setor imobiliário e o turismo, dando origem ao recente e ainda controverso Turismo Imobiliário ou Turismo Residencial (MAZÓN; ALEDO, 2005).

No litoral nordestino, "os empresários do segmento imobiliário estimam que os turistas estrangeiros já respondem por cerca de 30 a 50\% dos negócios" (CASTRO, 2006, p. 6). E a previsão é de crescer ainda mais, considerando o número de grandes investimentos que têm aportado na região desde a criação da ADIT. Segundo essa associação, "somente a soma dos projetos portugueses e espanhóis alcança $R \$ 3,7$ bilhões. Até 2014, estão previstas 7.250 novas unidades imobiliárias na região" (ADIT, 2008).

Tanto nos condo-resorts, quanto nas casas de praia e de campo, as segundas residências provocam problemas de subutilização da infraestrutura em alguns períodos e de sobre- utilização em outros. A distribuição espacial desses domicílios é composta por áreas heterogêneas, dispersas e segregadas dos núcleos urbanos, o que representa um desafio para os gestores e técnicos de planejamento compatibilizarem a oferta de serviços básicos pelo território, considerando os diferentes usos da população residente e temporária.

Se por um lado as segundas residências têm contribuído para melhorar a infraestrutura e a economia de alguns municípios nordestinos (com a abertura de estradas, o aumento do comércio, a oferta de empregos e de melhores serviços), por outro, elas também têm provocado o aumento da especulação imobiliária, da degradação dos ecossistemas e das mudanças nas atividades tradicionais.

Todos esses processos engendrados pelo lazer e pelo turismo nas segundas residências são resultados de práticas sociais que têm rebatimentos sobre o território, o qual é "[...] fundamentalmente um espaço definido e delimitado por e a partir de relações de poder" (SOUSA, 1995, p. 78). Poder esse aqui entendido no seu sentido multidimensional, que tem uma dupla conotação, material e simbólica, pois como nos lembra Haesbaert (2006, p. 79), "[...] o território pode ser concebido a partir da imbricação de múltiplas relações de poder, do poder mais material das relações econômicopolíticas ao poder mais simbólico das relações de ordem mais estritamente cultural".

Nesse sentido, podemos dizer que as segundas residências tanto geram um vínculo material (da posse de uma outra fração do território além daquela já ocupada pela primeira residência) quanto diversas representações simbólicas (status social, poder econômico, paz, isolamento, oportunidade de reencontro da família e da natureza perdida na cidade).

Com algumas ressalvas, podemos ainda associar essa visão híbrida de território, derivada de Haesbaert (2006), à noção de "território usado" proposta por Santos e Silveira (2001, p. 247), já que para eles "[...] quando quisermos definir qualquer pedaço do território, deveremos 
levar em conta a interdependência e a inseparabilidade entre a materialidade, que inclui a natureza, e o seu uso, que inclui a ação humana, isto é, o trabalho e a política".

O território usado é, para Santos (1996), sinônimo de espaço geográfico e de espaço banal, ou seja, um conjunto indissociável de sistemas de objetos e sistemas de ações que não tem apenas um sentido material ou funcional, mas também é dotado de significados e das experiências humanas. Essa aparente confusão conceitual entre espaço e território expressa, na verdade, uma crítica de Santos (2002, p. 15) ao legado de "conceitos puros", herdados da Modernidade, que atravessam séculos quase intocados.

Nos últimos trabalhos, Santos (2001; 2002) passou a atrelar o adjetivo "usado" ao conceito de território, tentando se desvencilhar de uma concepção materialista e políticoeconômica (de grande destaque na sua obra!) que restringe o território a uma superfície inerte onde ocorrem as ações do Estado e das empresas. A expressão território usado, por mais controvertida que pareça, busca reforçar o seu caráter impuro e totalizante de não ser apenas suporte ou receptáculo das atividades econômicas, mas um importante ator que reflete e condiciona as relações entre os homens e suas bases físicas e sociais.

No caso das segundas residências, podemos dizer que o território usado compreende um campo de forças que abriga e condiciona a ação dos visitantes, empresários, Poder Público e população receptora. Ele é apropriado e usado por todos esses atores em cooperação ou em conflito de interesses. O uso do território tanto o converte em mercadoria através da venda de casas e apartamentos para os turistas, quanto em moradia, espaço de descanso e de identidade para visitantes e nativos.

São os múltiplos usos do território que atribuem sua importância e o torna uma arena onde diferentes grupos sociais disputam seu domínio e ocupação. Por isso, Santos (2002, p. 15) destaca que "é o uso do território, e não o território em si mesmo que faz dele objeto da análise social".

Consideramos, então, que o território usado e a multiterritorialidade formam uma matriz teórica híbrida, relacional e multiescalar capaz de fundamentar uma análise dos velhos e novos usos das segundas residências.

O progresso técnico dos sistemas de transporte e comunicação aumentou a mobilidade entre a primeira e a segunda residência, intensificando os usos de múltiplos territórios de moradia, trabalho, lazer e turismo. Esse aumento da mobilidade possibilita às famílias locais da classe média vivenciar uma multiterritorialidade entre o domicílio permanente e suas tradicionais casas de temporada; assim como permite a uma elite global desfrutar da multiterritorialidade através dos diversos lugares que visita com frequência e das segundas residências que ali possui para a prática do turismo e/ou como investimento imobiliário.

A multiterritorialidade é aqui entendida no seu sentido abrangente de processo ou ação que corresponde, segundo Haesbaert (2006, p. 343344), à:

[...] possibilidade de acessar ou conectar diversos territórios, o que pode se dar tanto através de uma "mobilidade concreta", no sentido de um deslocamento físico, quanto "virtual", no sentido de acionar diferentes territorialidades mesmo sem deslocamento físico, como nas novas experiências espaçotemporais proporcionadas através do ciberespaço.

A partir desse entendimento, podemos dizer que as segundas residências intensificam a territoritorialização, ou melhor, a multiterritorialidade (entre a primeira e a segunda residência) como um processo que integra de forma concomitante a desterritorialização e a reterritorialização.

No Nordeste brasileiro, os dados e as informações supracitadas atestam a necessidade de aprofundar essa perspectiva de análise que também é compartilhada por Rodrigues (2006, 
p. 306) quando afirma que "o território turístico, em particular, sendo um espaço dominado e/ou apropriado, assume um sentido multiescalar e multidimensional que só pode ser devidamente apreendido dentro de uma concepção compósita, ou seja, de multiterritorialidade".

Não enfrentar esse debate específico e abrangente que as segundas residências há muito requerem é abrir mão de explorar o potencial explicativo que o conceito de multiterritorialidade oferece para compreender a complexidade de usos e relações que esses domicílios engendram na atualidade.

\section{Considerações finais}

Diante do exposto, podemos atribuir ao território o status de categoria geográfica que readquire importância na teoria social crítica contemporânea, (re)aproximando a Geografia da Filosofia e aquela das demais Ciências Humanas. Como toda categoria, o território não é estático, tendo os seus usos e significados alterados pela dinâmica da sociedade que, ao longo do tempo, redefine as relações de poder (materiais e simbólicas) entre os grupos sociais e seus espaços.
O território, cada vez mais, incorpora um sentido híbrido, relacional e multiescalar que enseja novas leituras e entendimentos, como território usado e multiterritorialidade que aqui brevemente apresentamos.

No Nordeste brasileiro, os velhos e novos usos do território pelas segundas residências incitam diversos estudos e questionamentos nesse sentido. A difusão dos condo-resorts na região altera a tradicional concepção da segunda residência como habitação de lazer, já que nesses complexos mistos de hotelaria e condomínio os turistas estrangeiros são os principais clientes. As novas formas de multipropriedade, assim como as redes e inovações que aumentam a mobilidade, tornam mais intensas e complexas a desterritorialização e a reterritorialização a que veranistas e turistas se submetem ao desfrutarem de uma segunda residência fora do seu lugar de moradia habitual.

Entender esses múltiplos usos do território ou a multiterritorialidade provocada pelas segundas residências é um desafio que urge e um convite a prosseguir com as pesquisas e reflexões.

\section{Notas}

${ }^{1}$ Também são usados os termos metadisciplina ou metaciência para expressar essas revisões e críticas epistemológicas/ontológicas. Japiassu (1991, p. 191) explica que "hoje em dia, cada ciência duplica-se numa disciplina fundamental correspondente que constitui sua metaciência. Esta se apresenta como um estudo vindo após uma ciência e interroga-se sobre seus princípios, seus fundamentos, suas estruturas e suas condições de validade, elevando-se a um nível superior". Na Geografia brasileira, recentemente, Carlos (2007, p. 11) vem defendendo a construção de uma metageografia a partir de uma reavaliação do marxismo e da crítica radical

2 Deve-se ainda registrar, dentre outros, as contribuições de Moreira (2007), Costa e Moraes (1984); Silveira (1999; 2003), Spósito (2004) e Martins (2007).
${ }^{3} \mathrm{Em}$ que pesem os distintos direcionamentos teóricos, muitas dessas críticas de Carlos (2007) se assemelham ao manifesto apresentado, em 2000, pelo grupo de Estudos Territoriais Brasileiros, coordenado por Milton Santos, que defendia o "papel ativo da Geografia" (BERNARDES, et al. 2001). Como já esperado, ambos os trabalhos terminam apontando seu olhar sobre a Geografia e o mundo como um caminho possível para "a superação das alienações vividas" e para se "encontrar um enfoque totalizador". Embora apresentem preciosas reflexões para a renovação da Geografia, essas análises também trazem ácidas e exageradas críticas a alguns segmentos do saber geográfico, a exemplo da abordagem geográfica do turismo que é rotulada por Carlos (2007, p. 9) como uma "certa Geografia do turismo". Isso demonstra, no mínimo, um ranço marxista de ainda atribuir menos importância 
científica às atividades elitistas ou terciárias; assim como, um descuido (ou descaso!) em não reconhecer os significativos trabalhos sobre o turismo produzidos pelos geógrafos nas últimas décadas (RODRIGUES, 1996; 2001). O turismo é uma atividade complexa e multifacetada que só recentemente tem ganhado a atenção científica e, cada vez mais, requer pesquisas e reflexões interdisciplinares. E a Geografia tem dado grandes contribuições nesse sentido, enfocando, especial "os sistemas de objetos e sistemas de ações" que resultam na "produção do espaço" pelo turismo e para o turismo. Os métodos e enfoques da Geografia do Turismo têm sido diversos, mas convergem para a formulação de propostas e críticas às "contradições da realidade e do capital". Ela é, portanto, um dos segmentos mais ativos da Geografia que não pode ser acusada de estar produzindo um refluxo ou uma fragmentação do pensamento geográfico, pois se há neste uma crise, é sempre um bom momento para superar os dogmatismos que impedem esforços conjuntos (e diversos!) para a reabilitação social da disciplina.

${ }^{4}$ As origens desse debate são apresentadas por Moreira (2007, p. 133-141) em um interessante texto intitulado de "o mal-estar espacial no fim do século $X X^{\prime \prime}$.

${ }^{5}$ Entre os geógrafos brasileiros que se destacam nos estudos epistemológicos da Geografia, não há um consenso sobre quais seriam os conceitos e/ou categorias centrais dessa disciplina. Silva (1986) sugere, entre outras, oito categorias fundamentais (espaço, lugar, área, região, território, habitat, paisagem e população); Corrêa (1995) propõe cinco conceitos-chave (paisagem, região, espaço, lugar e território); Moreira (2007) também cita três categorias básicas (espaço, território e paisagem); e Santos (1997) apresenta um leque diversificado de conceitos e categorias, como espaço, região, paisagem, lugar, território, configuração territorial, formação socioespacial, etc. Porém, conforme destacado, o espaço é a categoria comum a todos esses autores.
6 Segundo Claval (1999, p. 7), "os geógrafos dos anos sessenta atribuíram tudo ao espaço. Hoje em dia, eles falam mais comumente de território. Essa mudança reflete em parte os debates epistemológicos internos à geografia. Ela é, sobretudo, testemunha de uma profunda transformação do mundo, e de uma mutação correlata das maneiras de compreendê-lo".

7 Dentre as quais também se destacam as de inspiração fenomenológica, humanista ou cultural que discutem como a identidade, o cotidiano, o simbolismo e as representações sociais estabelecem nexos com o espaço (já que ele é sempre uma referência importante!) na construção das territorialidades ou das identidades territoriais. A esse respeito, ver os interessantes trabalhos de Mesquita e Brandão (1995), Claval (1999) e Haesbaert (1999; 2007).

8 Sem dúvidas, foi o geógrafo francês Claude Raffestin quem mais influenciou os geógrafos brasileiros a fazerem uma releitura do conceito de território nas últimas décadas, sobretudo através da sua obra Por uma Geografia do Poder. Mas, não podemos deixar de registrar, nesse período, as contribuições de Jean Gottman, Robert Sack e Giuseppe Demmateis, cujas obras foram analisadas por Haesbaert (2006) e Saquet (2007).

${ }^{9}$ Criada em junho de 2006 para realizar a união entre turismo e mercado imobiliário, a ADIT tem como foco a atração de investimentos, a melhora da infraestrutura do Nordeste e da legislação, especialmente, a ambiental.

10 Segundo Becker (1995, p. 10), "no Brasil, o aparecimento do fenômeno da segunda residência dá-se na década de 1950 sob a égide do 'nacional-desenvolvimentismo' que foi responsável pela implantação da indústria automobilística, pela ascensão do rodoviarismo como matriz principal dos transportes e pela emergência de novos estratos sociais médios e urbanos que, aos poucos, começariam a incorporar entre os seus valores sócio-culturais a ideologia do turismo e do lazer". 


\section{Bibliografia}

ADIT. Associação para o Desenvolvimento Imobiliário e Turístico do Nordeste Brasileiro. Clipping de notícias. Disponível em: http:// www.aditnordeste.com.br Acesso em: 02 out. 2008

ALTHUSSER, Louis. Filosofia e Filosofia espontânea das ciências. Lisboa: Presença, 1976.

ANDREU, Hugo García. Un acercamiento al concepto de Turismo Residencial. In: MAZÓN, Tomás; ALEDO, Antonio (Eds.). Turismo residencial y cambio social: nuevas perspectivas teóricas e empíricas. Alicante: Universidad de Alicante, Vicerrectorado de Extensión Universitária, 2005. p. 55-69

ASSIS, Lenilton Francisco de. Turismo de segunda residência: a expressão espacial do fenômeno e as possibilidades de análise geográfica. Revista Território. Rio de Janeiro: UFRJ, n. 11, 12 e 13, p. 107-122, Disponível em: http:// www.laget.igeo.ufrj.br/territorio/pdf/ N 1112 13/turismo.pdf Acesso: $16 \mathrm{dez} .2003$.

- Residências secundárias: expansão e novos usos no litoral cearense. In: SILVA; José B. da; DANTAS, Eustógio W. C.; ZANELLA; Maria E.; MEIRELES, Antônio Jeovah de A. (Orgs.). Litoral e sertão: natureza e sociedade no nordeste brasileiro. Fortaleza: Expressão Gráfica, 2006. p. 289-305

BECKER, Bertha K. Levantamento e avaliação da política federal de turismo e seu impacto na região costeira. Brasília: Ministério do Meio Ambiente, dos Recursos Hídricos e da Amazônia Legal, 1995.

BERNARDES, Adriana et. al. O papel ativo da Geografia: um manisfesto. Biblio $3 W$. Revista Bibliográfica de Geografía y Ciencias Sociales. n. 270. Universidade de Barcelona. Disponível em: http://www.ub.es/geocrit/b3w-270.htm Acesso: 29 nov. 2001
CARLOS, Ana Fani A. A "Geografia Crítica" e a crítica da geografia. In: COLÓQUIO INTERNACIONAL DE GEOCRÍTICA. 9. Porto Alegre, UFRGS. Disponível em: http://www.ub.es/ geocrit/9porto/anafani.htm Acesso: 21 dez. 2007.

CASTELLS, Manuel. A sociedade em rede. 6. ed. São Paulo: Paz e Terra, 2002.

CASTRO, Samira. Segunda residência é maior filão de negócios. Diário do Nordeste. Caderno Negócios, p. 6. Fortaleza, 13 jul. 2006.

CLAVAL, Paul. O território na transição da pósmodernidade. GEOgraphia. Ano 1, n. 2, Niterói: Ed. UFF, 1999. p. 7-26

CORRÊA, Roberto Lobato. Espaço: um conceitochave da Geografia. In: CASTRO, Iná Elias de et al. (Org.) Geografia: conceitos e temas. Rio de Janeiro: Bertrand Brasil, 1995. p. 15-47

COSTA, Wanderley Messias da; MORAES, Antônio Carlos Robert de. A valorização do espaço. São Paulo: Hucitec, 1984.

DELEUZE, Gilles; GUATTARI, Félix. O que é a Filosofia? 2. ed. Rio de Janeiro: Ed. 34, 2007.

FOUCAULT, Michel. Microfísica do poder. 16. ed. Rio de Janeiro: Graal, 2001.

GRANGER, Gilles-Gaston. A ciência e as ciências. São Paulo: Ed. UNESP, 1994.

HAESBAERT, Rogério. Identidades territoriais. In: ROSENDAHL, Zeny; CORRÊA, Roberto Lobato. Manifestações da cultura no espaço. Rio de Janeiro: Ed. UERJ, 1999. p. 169-190

Da desterritorialização à multiterritorialidade. In: ENCONTRO DE GEÓGRAFOS DA AMÉRICA LATINA, 10., 2005, Anais eletrônicos..., São Paulo: USP, 2005. 1 CD. p. 6774-6792 
HAESBAERT, Rogério. O mito da desterritorialização: do "fim dos territórios" à multiterritorialidade. 2. ed. Rio de Janeiro: Bertrand Brasil, 2006.

Multiterritorialidade, exclusivismo territorial e reconstrução de identidades. 2007. (Mimeo)

JAPIASSU, Hilton. Introdução ao pensamento epistemológico. 6. ed. Rio de Janeiro: Francisco Alves, 1991.

MARTINS, Élvio Rodrigues. Geografia e ontologia: o fundamento geográfico do ser. GEOUSP - Espaço e Tempo. São Paulo, n. 21, p. 33-51, 2007.

MAZÓN, Tomás; ALEDO, Antonio (Eds.). Turismo residencial y cambio social: nuevas perspectivas teóricas e empíricas. Alicante: Universidad de Alicante, Vicerrectorado de Extensión Universitária, 2005.

MESQUITA, Zilá; BRANDÃO, Carlos R. (Orgs.) Territórios do cotidiano: uma introdução a novos olhares e experiências. Porto Alegre: Ed. UFRGS, 1995.

MOREIRA, Ruy. Pensar e ser em Geografia. São Paulo: Contexto, 2007.

PETERSEN, Samanta. Turismo residencial atrai mercado imobiliário. O povo. Caderno Economia, p. 25. Fortaleza, 23 out. 2006.

RAFFESTIN, Claude. Por uma geografia do poder. São Paulo: Ática, 1993.

RATZEL, Friedrich. O solo, a sociedade e o Estado. Revista do Departamento de Geografia. São Paulo: n. 2., FFLCH-USP, 1983. p. 93-101

RODRIGUES, Adyr Balastreri (Org.). Turismo e Geografia: reflexões teóricas e enfoques regionais. São Paulo: Hucitec, 1996.

RODRIGUES, Adyr Balastreri. Geografia do turismo: novos desafios. In: TRIGO, Luiz G. Godoi
(Org.). Turismo: como aprender, como ensinar 1. São Paulo: SENAC, 2001. p. 87-122

- Turismo e territorialidades plurais lógicas excludentes ou solidariedade organizacional. In: LEMOS, Amália I. G.; ARROYO, Mônica; SILVEIRA, Maria L. América Latina: cidade, campo e turismo. São Paulo: CLACSO, 2006. p. $297-315$

SANTOS, Milton. O espaço geográfico como categoria filosófica. Terra livre 5 - O espaço em questão. São Paulo: AGB, 1988a. p. 9-20

(Org.). Novos rumos da Geografia brasileira. São Paulo: Hucitec, 1988b.

. El espacio banal, una epistemología de la existencia. In: Universitat de Barcelona, Solemne Investidura de Doctor Honoris Causa, novembro 1996.

. A natureza do espaço. 2. ed. São Paulo: Hucitec, 1997.

Por uma outra globalização. Rio de Janeiro: Record, 2000.

. O retorno do território. In: SANTOS, Milton; SOUZA, Maria Adélia A. de; SILVEIRA, Maria Laura. Território: globalização e fragmentação. 5. ed. São Paulo: Hucitec/ Annablume, 2002. p. $15-20$

SANTOS, Milton; SILVEIRA, María Laura. O Brasil: território e sociedade no início do século XXI. 3. ed. Rio de Janeiro: Record, 2001.

SANTOS, Milton; SOUZA, Maria Adélia A. de (Orgs.). O espaço interdisciplinar. São Paulo: Nobel, 1986.

SAQUET, Marcos Aurélio. Abordagens e concepções de território. São Paulo: Expressão Popular, 2007.

SILVA, Armando Corrêa da. O espaço fora do lugar. São Paulo: Hucitec, 1978. 
SILVA, Armando Corrêa da. As categorias como fundamentos do conhecimento geográfico. In: SANTOS, Milton; SOUZA, Maria Adélia A. de (Orgs.). O espaço interdisciplinar. São Paulo: Nobel, 1986. p. 25-37

SILVEIRA, María Laura. Uma situação geográfica: do método à metodologia. Revista Território. ano 4. n. 6., p. 21-28, jan./jun. 1999.

Por uma epistemologia geográfica. In: BERTONCELLO, Rodolfo; CARLOS, Ana Fani A. (Org.) Processos territoriales en Argentina $y$
Brasil. Buenos Aires: Instituto de Geografia, FFL, Universidad de Buenos Aires, 2003. p. 13-26

SOUSA, Marcelo Lopes de. O território: sobre espaço e poder, autonomia e desenvolvimento. In: CASTRO, Iná Elias de; GOMES, Paulo C. da Costa; CORRÊA, Roberto Lobato (Org.). Geografia: conceitos e temas. Rio de Janeiro: Bertrand Brasil, 1995. p. 77-116

SPÓSITO, Eliseu Savério. Geografia e Filosofia: contribuição para o ensino do pensamento geográfico. São Paulo: Ed. UNESP, 2004.

Trabalho enviado em Janeiro de 2009

Trabalho aceito em Agosto de 2009 